\title{
The Importance of Integrating Active Listening Skills during Parent-Teacher Conferences in a Simulated Environment
}

\author{
Kate D. Simmons, PhD \\ Professor of Special Education \\ Virtual Avatar Laboratory (VAL) Director \\ College of Education \\ Auburn University Montgomery \\ 7430 East Dr, Montgomery, AL 36117, USA \\ Carrie Hemmings, PhD \\ Assistant Professor of Counselor Education \\ College of Education \\ Auburn University Montgomery \\ 7430 East Dr, Montgomery, AL 36117, USA
}

\begin{abstract}
Over half of current teachers do not feel prepared to hold effective parent-teacher conferences. One way to prepare teacher candidates for difficult conversations is through live and virtual environment simulations. This study explores the use of virtual simulations in enhancing active listening skills among four undergraduate teacher candidates at a large rural southeastern university. Results indicated that participants felt they were more capable of managing an upset parent and more confident in employing active listening skills as a result of the live simulations.
\end{abstract}

Keywords: rephrasing, virtual environments, parent-teacher conferences

\section{Introduction}

According to the U.S. Department of Education (2015) public school teachers today are more disillusioned about their jobs than they have been in many years. Multiple opportunities for hands-on practice and active involvement are essential in learning for the teacher candidate. Teacher preparation programs should also incorporate videotaping and audio taping media to improve teaching and interview skills. The Council for the Accreditation of Educator Preparation (CAEP) encourages the use of technology to share best practices across stakeholders and facilitate ongoing learning.

In teacher preparation, more effective practices are needed for preparing teacher candidates (U.S. Department of Education 2009b). The challenge also lies in finding an effective mechanism that provides essential learning experiences and opportunities to refine the teacher candidate's techniques (Garland, Vasquez, \& Pearl, 2012). One way to support teacher candidates is through the use of a virtual environment (VEs). The goal is to provide teacher candidates the opportunity to learn new skills and craft their practice through the VEs. Currently, Auburn University at Montgomery is the only university in the state of Alabama that offers the Virtual Avatar Laboratory (VAL) for teacher candidates. What if teacher candidates could be provided with at least four years of practice through the VAL? Imagine the VAL utilizing "rounds," borrowing from the medical model, which would allow teacher candidates to learn in the field from a number of mentor teachers in a variety of settings. One of these settings is a parent-teacher conference. There are several strategies that can be used during a parent-teacher conference that teacher candidates have not been prepared to use. Implementing the VAL and designing a program for teacher candidates to practice conducting a conference would better prepare them for their first encounter with parents. 
In the VAL, teacher candidates can walk into a virtual room where everything looks like a standard conference room set up. Unlike the brick and mortar setting, the lab is a virtual setting and the parents are avatars. The virtual parents may behave in a way that offers teacher candidates an opportunity to practice their skills during a conference. Teacher candidates can interact with parent avatars and learn how to conduct an effective conference. In a VE, teacher candidates can practice the skills needed in a conference and perfect those skills through practice and observations.

Furthermore, computer simulation provides unique benefits in that performance can be recorded, compared with past performance, and tagged for analysis using a video tagging tool in conjunction with developed rubrics.

Parent- teacher relationships have always been valued in education. Having this relationship allows teachers to understand the student better (i.e.living situations, family situations, etc.). It also gives the parent(s) an insight as to what is going on in the classroom. This type of relationship is a working relationship and generally starts during a parent-teacher conference. This can be somewhat intimidating for novice teachers since there is not much practice given nor strategies given during their preservice years. It is important that teachers develop and perfect these strategies in order to conduct successful conferences and build relationships with the parent(s) (LawrenceLightfoot, 2004).

Gartmeier, et al. (2016) found in their study that about half of the teachers interviewed reported a lower selfconfidence in parent-teacher communication.

By implementing a VE program, the teacher candidate gains the opportunity to make a mistake without negatively affecting the parent-teacher relationship. It also allows the teacher candidate to become more comfortable in the setting and increase his/her self-confidence through constant practice. Many of skills needed to conduct a parentteacher conference can be taught during these VE simulations.

During a parent-teacher conference, one skill that teachers should use is active listening. This will allow the teacher to ask specific questions and rephrase what the parent(s) is asking or stating. Active listening skills will also let the parent(s) know you are listening to their concerns and want to help them by being able to rephrase their concerns. Lazoritz (2004) talks about using a "magic minute". This minute is used to allow the other parent(s) to talk first and express their comments and concerns (Lazoritz, 2004). This part often proves challenging initially because it takes practice for the teacher to be able to actively take notes and then rephrase and restate the parent's concerns. This "magic minute" demonstrates to the parent(s) that the teacher is engaged and concerned, and values what they have to say.

Active listening requires many skills in order to be effective. Anderson (2008) states there are four active listening skills; (1) make clear what the parent(s) is saying through open-ended questions (2) restate and confirm what the parent(s) have said by reiterating what you have heard (i.e. "If I understand you correctly..." or "So what you are saying is...") (3) reflect and identify with the parent to let them know you understand their concerns and/or feelings and (4) recap the meeting. When a teacher can implement all four of these skills, the parent-teacher relationship will develop, and the parent will feel that he/she has been heard. These skills also allow the teacher to stay true to the concerns of the meeting. It allows the teacher to respond cognitively rather than emotionally while also giving him/her information needed to help the parent and the student.

In conclusion, it is important that teacher candidates practice in simulated environments to practice skills needed to conduct a parent-teacher conference. These skills include active listening and rephrasing. This helps the teacher candidate understand the concerns the parent is trying to convey and helps eliminate emotion from any frustrations the parent(s) may have. The more practice a teacher candidate has, the more comfortable he/she will be when conducting a conference. The parent-teacher relationship is very important and helping the parent(s) know their concerns are heard is imperative. The use of simulated environments will enable teacher candidates to perfect these skills and be more successful when they encounter the parents of their students. The purpose of this study was to enhance an undergraduate course on Consultation and Collaboration with virtual simulations. Participants were given at least three opportunities to practice the active listening skill of rephrasing during a simulated parent-teacher conference.

\section{Research Questions}

1.Can understanding of active listening skills help teacher candidates run an effective parent-teacher conference?

2.Can live simulations effectively enhance a teacher candidate's ability to model effective listening? 


\section{Method}

\section{Participants and Setting}

A convenience sample was assembled for this study, and four participants selected were enrolled in an undergraduate level course (Consultation and Collaboration) at a large urban college in the Southeast region of the United States. Participants were required to be currently enrolled in the College of Education and have no previous formal experience or preparation in practicing active listening skills. All volunteer participants were females ranging in age from 23 to 25 .

\section{Setting and Materials}

The Virtual Avatar Laboratory (VAL) served as the platform for 17 teacher candidates enrolled in the course. Participants learned about consultation and collaboration through a series of course lectures. More specifically, teacher candidates were given a one-hour lecture on the importance of active listening skills. Teacher candidates were also coached through a series of exercises to implement active listening skills. For this particular study, teacher candidates used the skills taught during the lecture in the VAL.

\section{Scenario Design. Stacy Lewis (mother) and Ed Lewis (son)}

Ed is very sensitive, humble, respectful, and polite. He doesn't require a lot of attention or praise, but is often passively engaged and ready to answer when called upon. Ed's very into basketball (though he is not a classic "jock" in any way), his large family, and the Air Force (he wants to be a pilot one day like his Uncle James). He's soft spoken and sweet. His slower speech pattern is indicative of his thoughtful and deliberate personality he's still very smart.

His reading scores are of concern to the general education and special education teacher. The office has just called to say that his mother, Stacy Lewis is here to discuss his grade. His grade thus far is a C and he usually makes As in his courses. Ed seems to be having difficulty with higher level comprehension and "what might happen next". His ability to recall main idea and characters is great. He is doing great in all of his other classes. Ed also seems distracted and slow to start his work, which may be why is he exhibiting poor performance. This is strange considering he is always reading a book on basketball and sports.

Participant goal: Reassure Ms. Lewis through using the skill of rephrasing. Each participant had three opportunities to rephrase during the simulation.

\section{Schedule}

Teacher candidates first began by participating in class lectures related to collaboration. A one-hour lecture focused on defining active listening skills (rephrasing repeating, etc.). Teacher candidates then had the opportunity to practice active listening skills through live simulations. Simulations lasted from 7-10 minutes in length and the After Action Review (ARR) discussions were led after each simulation. The ARR is a review that asks participants to reflect on what they expected to happen, what really happened, and what could be improved upon. Afterwards, participants filled out the ARR Active Listening Survey.

\section{Design}

Because live simulation research within the field of education is a relatively young, this study hopes to add to the small but established research base. This qualitative case study offers the opportunity to collect data at a single point in time from a specified population. This methodology provides tools for researchers to study complex phenomenon within their context (Baxter \& Parks, 2008). The one-page ARR Active Listening Survey was provided to each participant after each simulation. This survey consisted of five open ended questions. After each simulation, the instructor and another special education faculty member gave feedback to enhance reliability. Additionally, teacher candidates discussed their thoughts and provided feedback. 


\section{Results}

\begin{tabular}{|l|l|l|l|l|l|}
\hline & Gender & Age & Race & $\begin{array}{l}\text { Ability to } \\
\text { define } \\
\text { rephrasing }\end{array}$ & Ability to Model rephrasing \\
\hline Teacher candidate 1 & F & 20 & African American & Yes & $3 / 3$ \\
\hline Teacher candidate 2 & F & 19 & Caucasian & Partial & $3 / 3$ \\
\hline Teacher candidate 3 & F & 21 & Caucasian & Yes & $3 / 3$ \\
\hline Teacher candidate 4 & F & 23 & African American & Yes & $2 / 3$ \\
\hline
\end{tabular}

Table 1

The data gathered strongly supports the coupling of learning and practicing skills and answers the research questions. As outlined in Table 1, three out of the four participants could successfully define active listening. Candidate four missed the third opportunity to practice the rephrasing skill during the simulation.

In answer to the two stated research questions, all four teacher candidates were able to understand active listening skills which in turned helped them run an effective parent-teacher conference. Survey results also showed that live simulations were effective in enhancing their ability to model effective listening. Additionally, all candidates were able to pinpoint the strengths and weaknesses of their simulation.

The following are comments made by some of the teacher candidates:

- "Wording and clearness: I need to be better at word use and to give clear and direct information and instruction."

- "She liked when I rephrased it...she was happy that I listened"

- "I need to be more confident as a teacher...start to talk like a professional"

- "I learned how to engage in a meaningful parent conference. Indeed, I gained so much knowledge today. I am comfortable now and at first, I was very afraid of conferences."

- "...our interaction and communication was efficient and we determined a solution to help Ed."

\section{Limitations}

The small sample size is a limitation to the applicability of the findings to larger populations. There is no adequate statistical power to compare means through t-tests to determine statistical significance between intervention groups. To enhance the results of similar studies, we recommend a larger sample size. The researchers do not know if other lectures related to collaboration, or other variables, influenced the successful simulation beyond the one-hour active listening lecture. It is unknown if additional variables impacted the findings of the study. It is difficult to ascertain personality differences with active listening, when some personalities are more adept to listening first than others. The researchers would have liked to have had some male participants. Finally, allowing for multiple opportunities to practice active listening might have further ingrained those specific skills.

\section{Conclusion}

Although this is a relatively small case study, findings indicate that live simulations allow teacher candidates to practice the skill of active listening proved to enhance their learning. The ability to lecture and then model good (or see ineffective) active listening skills serves as a catalyst to in improving teacher preparation. Although one participant had difficulty defining active listening, she had no difficulty in empathizing and working through solutions with the parent. This brings up the alluding question; "Is teaching a science or an art?"or book smart versus street smart). Teacher candidates sometimes do not test well, or have difficulty articulating a concept, but have little difficulty modeling that skill in field experiences. Mostgrade " $C$ " teacher candidates in the program appear to be more effective teachers than some grade "A" level teacher candidates. Maybe, adding a modeling component to teacher preparation programs is a more accurate way of assessing teacher candidate learning.

Teacher preparation programs must continue to examine weaknesses in preparation programs and consider using live simulations to enhance student competency. More attention can be paid to the longevity of these skills. Providing opportunities to practice effective listening skills only helps to strengthen preparation programs. 


\section{References}

Anderson, J. (2008). Developing active listening skills. IDEA Fitness Journal, 5(5), 85-87.

Baxter, P, \& Jack, S. (2008). Qualitative case study methodology: Study design and implementation for novice researchers. The Qualitative Reports, 13(4), 544-559.

Garland, K.V., Vasquez, E., and Pearl, C. (2012). Efficacy of individualized clinical in a virtual reality classroom for increasing teachers' fidelity of implementation of discrete trial teaching. Education and Training in Autism and Developmental Disabilities, 47,(4), 502-515.

Gartmeier, M., Gebhardt, M. \&Dotger, B. (2016). How do teachers evaluate their parent communication competence? Latent profiles and relationships to workplace behaviors. Teaching And Teacher Education, 55207-216. doi:10.10.16/j.tate.2016.01.009

Lawrence-Lightfoot, S. (2004). Building bridges from school to home. Instructor, 114(1), 24.

Lemmer, E. M. (2012). Who's doing the talking? Teacher and parent experiences of parent-teacher conferences. South African Journal of Education, 32(1), 83-96.

Lazoritz, Stephen. (2004). Dealing with angry patients. Physician Executive, 30(3), 28.

U.S. Department of Education, Office of Special Education and Programs. (2009). 2009 Part B Child Count, students ages 6-21, 50 States, DC, PR, BIE schools. www.IDEAdata.org

U.S. Department of Education, Office of Postsecondary Education (2015).Teacher Shortage Areas Nationwide Listing 1990-1991 through 2015-2016. http://www2.ed.gov/about/offices/list/ope/pol/tsa.doc 